\title{
Epidemiology of infections by HIV, Syphilis, Gonorrhea and Lymphogranuloma Venereum in Barcelona City: a population-based incidence study
}

Marc Martí-Pastor ${ }^{1,2}$, Patricia García de Olalla ${ }^{1,3^{*}}$, Maria-Jesús Barberá ${ }^{4}$, Christian Manzardo ${ }^{5}$, Inma Ocaña ${ }^{4}$ Hernando Knobel ${ }^{6}$, Mercè Gurguí ${ }^{7}$, Victoria Humet ${ }^{8}$, Martí Vall ${ }^{4}$, Esteban Ribera ${ }^{4}$, Judit Villar ${ }^{6}$, Gemma Martín $^{6}$, Maria A. Sambeat ${ }^{7}$, Andres Marco ${ }^{8}$, Alvaro Vives ${ }^{9}$, Mercè Alsina ${ }^{5}$, Josep M. Miró ${ }^{5}$, Joan A. Caylà ${ }^{1,3}$ and and the HIV Surveillance Group

\begin{abstract}
Background: The aim of this study was to determine the evolution of HIV infection, gonorrhea, syphilis and lymphogranuloma venereum (LGV), and their epidemiological characteristics in Barcelona city.

Methods: Population-based incidence study of all newly occurring diagnoses of HIV infection, syphilis, gonorrhea and LGV detected in Barcelona between January 2007 and December 2011. A descriptive analysis was performed. The annual incidence rates per 100,000 inhabitants were calculated by sex, sexual conduct and educational level. To estimate global sex-specific rates we used the Barcelona city census; for the calculation of rates by sexual conduct and educational level we used estimates of the Barcelona Health Interview Survey. Trends were analysed using the chi-squared test for linear trend.
\end{abstract}

Results: HIV. $66.8 \%$ of the HIV cases were men who had sex with men (MSM). The incidence rates in MSM over the study period were from $692.67 / 100,000$ to $909.88 / 100,000$ inh. Syphilis. $74.2 \%$ of the syphilis cases were MSM. The incidence rates in MSM were from 224.9/100,000 to $891.97 / 100,000$ inh. and the MSM with a university education ranged from 196.3/100,000 to 1020.8/100,000. Gonorrhea. $45.5 \%$ of the gonorrhea cases were MSM. The incidence rates in MSM were from 164.24/100,000 to 404.79/100,000 inh. and the MSM with university education ranged from 176.7/100,000 to 530.1/100,000 inh.. Lymphogranuloma venereum (LGV). $95.3 \%$ of the LGV cases are MSM. The incidence rates in MSM were from 24.99/100,000 to 282.99/100,000 inh. and the MSM with university education ranged from $9.3 / 100,000$ to $265 / 100,000$ inh.

Conclusion: An increase in cases of STI was observed. These STI mainly affected MSM with a university education. Continuing to monitor changes in the epidemiology of STI, and identifying the most affected groups should permit redesigning preventive programs, with the goal of finding the most efficient way to reach these population groups.

Keywords: Sexually transmitted diseases, HIV, Syphilis, Gonorrhea, Lymphogranuloma venereum, Sexual behavior, Epidemiology, Incidence

\footnotetext{
* Correspondence: polalla@aspb.cat

${ }^{1}$ Epidemiology Service, Agencia de Salut Pública de Barcelona, PI. Lesseps, 1, 08023 Barcelona, Spain

${ }^{3}$ Consorcio de Investigación Biomédica en Red de Epidemiología y Salud

Pública (CIBERESP), Barcelona, Spain

Full list of author information is available at the end of the article
} 


\section{Background}

Over the last decade an increase has been observed in sexually transmitted infections (STI) in various Western countries [1-3]. In these countries, the majority of cases occur in metropolitan areas, men who have sex with men (MSM) being the group most affected [4-6].

The rise in STI has been influenced by the increase in risky sexual conduct (increase in number of partners, and subgroups engaging in more risky sexual practices) $[7,8]$, probably resulting from a relaxation in practising safe sex because of a false sensation of safety due to the existence of highly active antiretroviral therapy (HAART). Furthermore, HIV infection is associated with other STI, since they increase the risk of acquiring and transmitting HIV [2, 8, 9].

The aim of this study was to determine the evolution of HIV infection, gonorrhea, syphilis and lymphogranuloma venereum (LGV), and their epidemiological characteristics in a large city.

\section{Methods}

Barcelona is a city of $1,615,985$ inhabitants [10] in which the obligatory notification of syphilis, gonorrhea and LGV has been nominal since 2007, and notification of HIV infection, voluntary between 2001 and 2009, has been obligatory and nominal since 2010 [11].

This is a population-based incidence study of all newly occurring diagnoses of infection by sexually transmitted HIV, syphilis, gonorrhea and LGV detected by the epidemiological surveillance system among residents of the city of Barcelona between January 2007 and December 2011. Cases of vertical and intravenous transmissions of HIV infection were excluded, as were cases diagnosed with AIDS, and cases of late latent, terciary and congenital syphilis. Doctors who diagnosed a case completed a questionnaire which collects sociodemographic and clinical variables: sex, date of birth, country of birth ((1) Spain; (2) Western Europe, United States, Canada and Australia; (3) Eastern Europe; (4) Latin America; (5) Other) and sexual conduct ((1) MSM; (2) men who only have sex with women (MSW); and (3) women who have sex with men (WSM)). Educational level ((1) no studies; (2) primary studies; (3) secondary studies; (4) university studies), number of sexual partners in the last 12 months and use of condom in most recent sexual contact were collected in cases of syphilis, gonorrhea and LGV, but not in cases of HIV infection.

A descriptive analysis was performed, calculating annual incidence rates per 100000 inhabitants, by sex, sexual behaviour category and educational level. In order to estimate sex-specific rates we used population figures from the Barcelona city local census [10]; for the calculation of rates by sexual conduct and educational level we used estimates of the MSM population (5.3\%) obtained through the Barcelona Health Interview Survey, along with their $95 \%$ confidence intervals (CI) [12]. Trends were analysed using the chi-squared test for linear trend.

All analyses were peformed using the SPSS statistical package, version 18 [13]. HIV, syphilis, gonorrhea and LGV are mandatory notifiable infections for health professionals in compliance with Article 13 of the law 67/2010 (25 ${ }^{\text {th }}$ May 2010) of the Health Department of Generalitat de Catalunya. All data was handled maintaining strict confidentiality according to the ethical principles of the Helsinki Declaration of 1964 revised by the World Medical Organization in Edinburgh, 2000 and Law 15/1999 of Data Protection in Spain [14].

\section{Results}

HIV

A total of 1560 cases were detected, of whom $89 \%$ $(n=1388)$ were men, and of these $79 \%$ (1096) declared themselves to be MSM (7.3 \% of all MSM had sex with both males and females and $92.7 \%$ had sex with men only). MSM had a mean age of 34.7 years (SD:8.7), WSM a mean age of 36.6 years (SD:9.9) and the MSW of 38.6 years (SD:12.3), differences between groups being statistically significant $(p$ $<0.001$ ) (Table 1). Regarding country of birth, $50 \%$ $(n=548)$ of the MSM, $58.3 \%(n=133)$ of the MSW and $50 \%(n=86)$ of the WSM had been born in Spain (Table 1). However, the highest global rates recorded during the study period were found among subjects from Subsaharan Africa (238.51/100,000 inh.) and from Latin America (77.77/100,000 inh.), while the rate for those born in Spain was only 11.9/ 100,000 inhabitants.

Overall, a significant $10 \%$ rise in the rate was observed, from 20/100,000 inh. in 2007 to 22/100,000 inh. in $2011(p=0.015)$. Among men, there was an increase of $25 \%$, while among women a decline of $38 \%$ was observed (Fig. 1).

MSM accounted for the highest proportion of cases ( $66.8 \%$ of the total), as well as the highest rates, with an increase of $31 \%$ over the study period (from 692.67/ 100,000 to $909.88 / 100,000$ inh.) $(p<0.001)$ (Fig. 2).

\section{Syphilis}

A total of 1124 cases were detected, $91.9 \%(n=1033)$ being men, among whom $80.7 \%$ (834) declared themselves to be MSM (6.7\% of all MSM had sex with both males and females and $93.3 \%$ had sex with men only). The MSM had a mean age of 36.4 years (SD:9.3), MSW had a mean age of 37.3 years (SD:12.3), and the WSM of 36.4 years (SD:11); differences between the groups were not significant 
Table 1 Epidemiological characteristics of cases diagnosed of HIV, syphilis, gonorrhea and lymphogranuloma venereum (LGV), by sexual conduct and sex. Barcelona, 2007-2011

\begin{tabular}{|c|c|c|c|c|c|c|c|c|c|c|}
\hline \multirow[t]{5}{*}{ Epidemiological characteristics } & \multicolumn{3}{|l|}{ HIV } & \multicolumn{3}{|l|}{ Syphilis } & \multicolumn{3}{|l|}{ Gonorrhea } & \multirow{4}{*}{$\begin{array}{l}\text { LGV } \\
\text { Men } \\
150 \\
\text { MSM* }^{*}\end{array}$} \\
\hline & \multicolumn{2}{|l|}{ Men } & \multirow{3}{*}{$\begin{array}{l}\text { Women } \\
172 \\
\text { WSM }^{* * *}\end{array}$} & \multicolumn{2}{|l|}{ Men } & \multirow{3}{*}{$\begin{array}{l}\text { Women } \\
91 \\
\text { WSM }^{* * *}\end{array}$} & \multicolumn{2}{|l|}{ Men } & \multirow{3}{*}{$\begin{array}{l}\text { Women } \\
130 \\
\text { WSM }^{* * *}\end{array}$} & \\
\hline & \multicolumn{2}{|l|}{1388} & & \multicolumn{2}{|l|}{1033} & & \multicolumn{2}{|l|}{1031} & & \\
\hline & $\mathrm{MSM}^{*}$ & $\mathrm{MSW}^{* *}$ & & $\overline{M^{\prime} M^{*}}$ & $M S W^{* *}$ & & $\mathrm{MSM}^{*}$ & $M S W^{* *}$ & & \\
\hline & 1096 & 228 & 172 & 834 & 112 & 91 & 528 & 244 & 130 & 143 \\
\hline \multicolumn{11}{|l|}{ Age } \\
\hline Mean (SD) & $34.7(8.7)$ & $38.6(12.3)$ & $36.6(9.9)$ & $36.4(9.3)$ & $37.3(12.3)$ & $36.4(11)$ & $32.7(7.5)$ & $31.8(9.4)$ & $31.2(10)$ & $37.1(7.5)$ \\
\hline \multicolumn{11}{|l|}{ Age group (\%) } \\
\hline $15-24$ years & $120(10.9)$ & $21(9.2)$ & $18(10.5)$ & $49(5.9)$ & $15(13.4)$ & $11(12.1)$ & $57(10.8)$ & $51(20.9)$ & $28(21.5)$ & $3(3.1)$ \\
\hline $25-34$ years & $503(45.9)$ & $80(35.3)$ & $67(39)$ & $343(41.1)$ & $35(31.3)$ & $33(36.3)$ & $282(53.4)$ & $120(49.2)$ & $61(46.9)$ & $54(37.8)$ \\
\hline $35-44$ years & $346(31.6)$ & $70(30.5)$ & $52(30.2)$ & $311(37.3)$ & $35(31.3)$ & $31(34.1)$ & $150(28.4)$ & $46(18.9)$ & $24(18.5)$ & $65(45.5)$ \\
\hline 45 years or older & $127(11.6)$ & $57(25)$ & $35(20.3)$ & $131(15.7)$ & $27(24.1)$ & $16(17.6)$ & $39(7.4)$ & $27(11.1)$ & $16(12.3)$ & $21(14.7)$ \\
\hline \multicolumn{11}{|l|}{ Country of Birth (\%) } \\
\hline Spain & $548(50)$ & $133(58.3)$ & $86(50)$ & $421(50.5)$ & $37(33)$ & $19(20.9)$ & $286(54.2)$ & $134(54.9)$ & $52(40)$ & $79(55.2)$ \\
\hline Western Europe, United States, Canada and Australia & $131(12)$ & $8(3.5)$ & $7(4.1)$ & $124(14.9)$ & $7(6.3)$ & $3(3.3)$ & $89(16.9)$ & $13(5.3)$ & $12(9.2)$ & $25(17.5)$ \\
\hline Eastern Europe & $22(2)$ & $18(8.8)$ & $6(3.5)$ & $18(2.2)$ & $7(6.3)$ & $9(9.9)$ & $13(2.5)$ & $8(3.3)$ & $3(2.3)$ & $2(1.4)$ \\
\hline Latin America & $369(33.7)$ & $43(18.9)$ & $41(23.8)$ & $243(29.1)$ & $31(27.7)$ & $51(56)$ & $116(22)$ & $50(20.5)$ & $54(41.5)$ & $35(24.5)$ \\
\hline Sub-saharan Afrika & $6(0.5)$ & $11(4.8)$ & $25(14.5)$ & $1(0.1)$ & $1(1)$ & $2(2.2)$ & $1(0.2)$ & $10(4.1)$ & $1(0.8)$ & $0(0)$ \\
\hline Other & $19(1.7)$ & $13(5.7)$ & $7(4.1)$ & $17(2.1)$ & $27(23.2)$ & $7(7.7)$ & $10(1.9)$ & $22(9)$ & $3(2.3)$ & $1(0.7)$ \\
\hline Missing & $1(0.1)$ & $0(0)$ & $0(0)$ & $10(1.2)$ & $3(2.6)$ & $0(0)$ & $13(2.5)$ & $7(2.6)$ & $5(3.8)$ & $1(0.7)$ \\
\hline \multicolumn{11}{|l|}{ Condom use } \\
\hline Yes & & & & $201(24.1)$ & $12(10.7)$ & $11(15.5)$ & $96(18.2)$ & $31(12.7)$ & $37(31.6)$ & $12(8.4)$ \\
\hline No & & & & $425(51)$ & $67(59.8)$ & $37(40.7)$ & $348(65.9)$ & $167(68.4)$ & $65(58.1)$ & $98(68.5)$ \\
\hline Missing & & & & $208(24.9)$ & $33(29.5)$ & $43(47.3)$ & $84(15.9)$ & $46(18.9)$ & $25(19.3)$ & $33(23.1)$ \\
\hline \multicolumn{11}{|l|}{ Number of sexual partners } \\
\hline Median (min - max) & & & & $10(1-400)$ & $2(1-60)$ & $1(1-100)$ & $9(1-210)$ & $3(1-50)$ & $2(1-100)$ & $15(1-100)$ \\
\hline
\end{tabular}

*MSM: Men who have sex with men

${ }^{*}$ MSW: Men who have sex with women

***WSM: Women who have sex with men

SD Standard deviation 


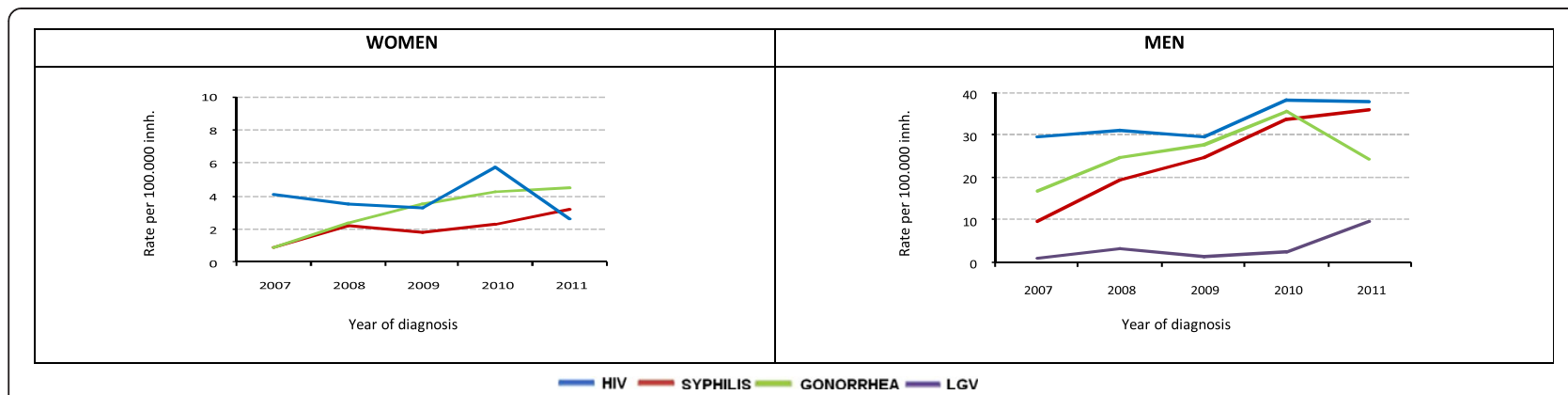

Fig. 1 Incidence of syphilis, gonorrhea, lymphogranuloma venereum and HIV by sex. Barcelona, 2007-2011

$(p=0.37)$. Regarding country of birth, $50.5 \%(421)$ of MSM and $33 \%$ (37) of MSW had been born in Spain, while $56 \%(n=51)$ of WSM had been born in Latin America (Table 1). However, the highest rates were found among cases born in Subsaharan Africa (111.65/100,000 inh.) and in Latin America (57.91/ 100,000 inh.) both well above the rate for those born in Spain (7.9/100,000 inh.).

Over the period studied, the rate rose by $267 \%$, from $6 / 100,000$ to $22 / 100,000$ inhabitants $(p<0,001)$. Among men there was a rise of $273 \%$, in women of $240 \%$ (Fig. 1).

The MSM accounted for the highest proportion of cases (74.2\% of the total), as well as the highest rates, a rise of $296 \%$ being observed over the period (from $224.9 / 100,000$ to $891.97 / 100,000$ inh.) $(p<0.001)$. Thus, in 2011 their rate was 175 times higher than that of WSM (5.11/100,000 inh.) and 96 times higher than MSW (9.29/100,000 inh.) (Fig. 2). In relation to educational level, MSM with a university education presented the highest rates, ranging from 196.3/100,000 inh. in
2007 to $1020.8 / 100,000$ inh. in 2011, representing an increase of $420 \%$ in this group $(p<0.001)$ (Fig. 3).

Regarding use of a condom the last time they had sex, $24.1 \%$ of MSM, $10.7 \%$ of MSW and $15.5 \%$ of WSM reported doing so. The median number of sexual partners in the last 12 months was 10 among MSM (min:1; $\max : 400), 2$ among MSW (min: 1; $\max : 60$ ), and 1 among WSM (min: 1; max: 100), this information being available in $75.8 \%$ of cases (Table 1).

\section{Gonorrhea}

A total of 1161 cases were detected, $88.8 \%(n=1031)$ of whom were men and of these $51.2 \%$ (528) declared themselves to be MSM (8.1 \% of all MSM had sex with both males and females and $91.9 \%$ had sex with men only). The mean age of the MSM was 32.7 years (SD:7.5), of MSW was 31.8 (SD:9.4) and of WSM was 31.2 (SD:10), with no significant differences between groups $(p=0.21)$. Regarding country of birth, $54.2 \%$ (286) of the MSM and $54.9 \%$ (134) of the MSW were born in Spain, while 41.5 \% (54) of the WSM were born

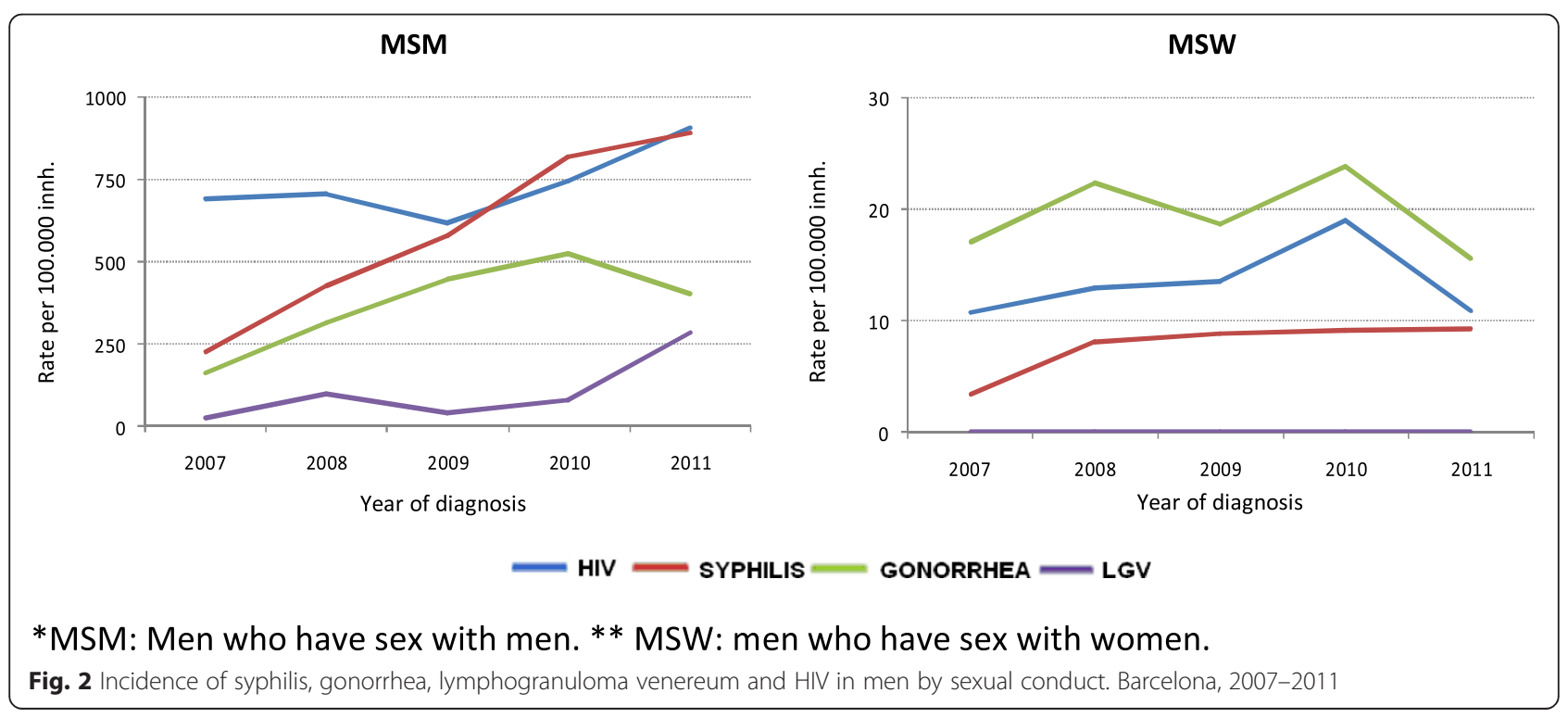




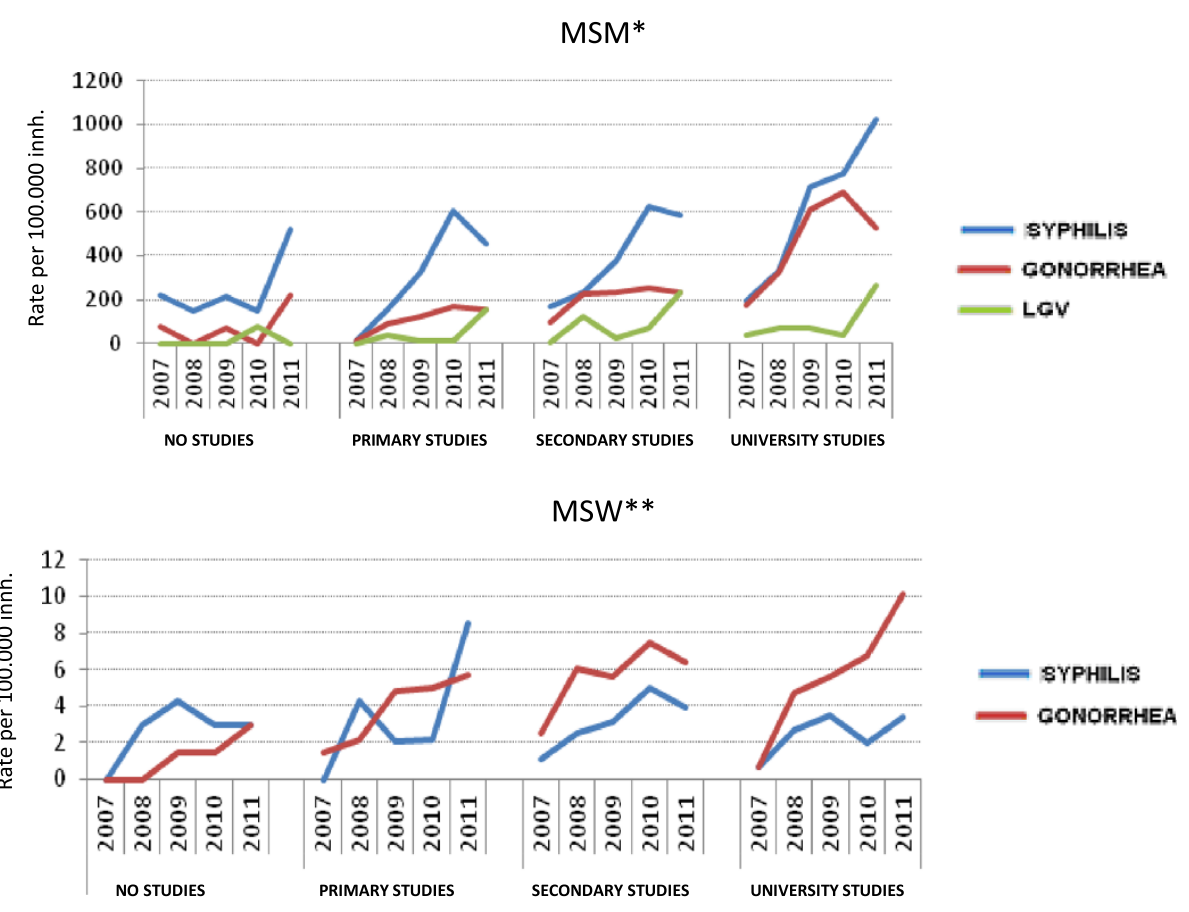

*MSM: Men who have sex with men. ** MSW: men who have sex with women.

Fig. 3 Incidence of syphilis, gonorrhea, lymphogranuloma venereum in men by sexual conduct and education level. Barcelona, 2007-2011

in Latin America (Table 1). However, Latin America was the region of birth which presented the highest incidence rates $(44.61 / 100,000$ inh.) followed by Eastern Europe (40.66/100,000 inh.), both rates being higher than that among subjects born in Spain $(9.5 / 100,000$ inh.).

During the study period, a significant increase of $50 \%$ was observed in the rates, which rose from 10/100,000 inh. to $15 / 100,000$ inh. $(p<0.0001)$. The increase among men was therefore $45 \%$, while among women it was 353 \% (Fig. 1).

The MSM group accounted for $45.5 \%$ of all recorded cases and present the highest incidence rates, which rose by $146 \%$ over the study period (from 164.24/100,000 to 404.79/100,000 inh.) $(p<0.01)$ (Fig. 2). Hence, in 2011 their rate was 60 times higher than that of WSM (6.75/ 100,000 inh.), and 26 times higher than that of MSW (15.62/100,000 inh.) (Fig. 2). Regarding educational level, the MSM with a university education presented the highest rates, which ranged from 176.7/100,000 inh. in 2007 to $530.1 / 100,000$ inh. in 2011, representing an increase of $200 \%(p<0.001)$ (Fig. 3).

In relation to whether they used a condom the last time they had sex, $18.2 \%$ of MSM, $12.7 \%$ of MSW and $31.6 \%$ of WSM report doing so. The median number of sexual partners in the last 12 months was 9 among MSM (min: 1; max: 1000), 3 among MSW (min: 1;max:
50) and 2 among WSM (min: 1;max: 100), this information being available in $78.6 \%$ of cases (Table 1 ).

\section{Lymphogranuloma venereum}

A total of 150 cases were detected, all corresponding to men, $95.3 \%$ of whom declared themselves to be MSM ( $0.7 \%$ of all MSM had sex with both males and females and $99.3 \%$ had sex with men only). In seven cases this information was not available. The mean age was 37 years; $56.7 \%$ of cases were born in Spain (Table 1); overall incidence rate was $1.3 / 100,000$ inhabitants. The highest incidence rate corresponded to cases born in Western Europe (8.13/100,000 inh.) follow by those born in Latin America (5.89/100,000 inh.). During the study period there was an increase in the incidence among MSM of $1032 \%$ (from 24.99/100,000 inh. in 2007 to 282.99/100,000 inh. in 2011) (Fig. 2).

In relation to educational level, cases with a university education presented the highest rates, which ranged from 39.3/100,000 inh. in 2007 to 265/100,000 inh. in 2011 , representing an increase of $574 \%(p<0.001)$ (Fig. 3).

Regarding whether they used a condom the last time they had sex, $8.4 \%$ of cases reported doing so. Information on the number of sexual partners in the last 12 months was available for $45.9 \%(n=69)$ cases, the 
median number among MSM being 15 (min: 1; max: 100) (Table 1).

\section{Discussion}

With respect to other cities in developed countries, in 2010 our HIV incidence rates were higher than in London $(15 / 100,000$ inh.) [15] and lower than those in New York (42.6/100,000 inh.) [16]. In the case of syphilis, our incidence rates were lower (London: 14/100,000 inh.; New York: 130/100,000 inh) $[4,6,7,17]$. However, with respect to Spain as a whole, our incidence rates were 3.5 times higher for both syphilis and gonorrhea [18].

The ratio of gonorrhea to syphilis cases was changing over time, as seen in the rest of Europe where the ratio had been decreasing [5]. In Barcelona, in 2007 the ratio was 1.6, in 2008 was 1.2, in 2009 was 1.1, in 2010 was 1 and in 2011 was 0.7 . This decrease was clearly related to sexual conduct variable due to an increase in the proportion of MSM was observed over the five years and the syphilis had a higher proportion of MSM than gonorrhea.

The group of MSM were the most affected, as found in other large cities of Western countries [6,7]. The rise in STI incidence could be influenced by a rise in risky sexual conduct, including: an increase in number of sexual partners, subgroups engaging in more risky sexual practices and a higher frequency of unprotected sexual practices $[8,19-21]$. This had been observed in recent years with epidemics such as that of LGV [22] and outbreaks of hepatitis [23], which were indicative of a rise in risky sexual conduct in this group. This fact may be explained according to various sociological theories, which suggest that risky sexual conduct among MSM could constitute a mechanism to cope with or escape from stress resulting from the perception of social rejection $[24,25]$.

Another possible reason that justifies the observed increase is the failure of HIV prevention strategies (e.g. sero-sorting/positioning, treatment as prevention, pre/ post-exposure prophylaxis, etc.). There is still some way to go in identifying which of these upstream interventions are effective, how they may be implemented within or alongside existing health care systems, and what impact, if any, they are likely to have on STD transmission. Today, effective HIV prevention requires a combination of behavioral, biomedical, and structural intervention strategies.

In regard to educational level, MSM with a university education were the most affected group. At national level it had also been observed that people with more education (secondary and university studies) presented the highest incidence rates [26]. Possible reasons which could justify this result included: greater access to health services by the better educated population, over-estimation of the university population, being a self-reported variable and/or that the population with more resources was more careless about the problem of STI due to the efficiency of antiretroviral therapies and thus had less fear of HIV.

With respect to place of birth, it was notable that half the STI cases occurred among foreigners. For this reason it was necessary to ensure access to health services among this particularly vulnerable group.

Among the limitations of the present study, one was the possibility of an over-estimation of university level education, since the variable was self-reported as already mentioned. However, we believed that the rates were close to the true values, as they were similar to those in the rest of the country [26]. Another limitation of the study was the large number of missing values in two self-reported variables: number of sexual partners and condom use. Finally, we must mention the possible existence of recall bias in the self-reported variables (educational level, number of sexual partners, condom use and sexual conduct).

\section{Conclusions}

An increase in cases of STI was observed in the city of Barcelona over the period studied, particularly cases of syphilis and LGV. And the increase in STI was observed in all categories of sexual conduct, except HIV-infected WSM for which a reduction during the study period was observed.

MSM constituted the group most affected by infections of this type, particularly those with a university education. This suggests that although people were informed about sexually transmitted infections, they did not take sufficient preventive measures to avoid them, meaning that a change is probably necessary in the different preventive messages that they currently receive.

This study shows that STI must be a priority in public health. In Barcelona, different preventive programs have been developed to try to reduce the incidence of STIs, such as a sauna program and a partner notification program [27]. We have also created 3 specialized units of STI to increase early diagnosis and reduce damage and in recent years the collaboration between public health services and community associations has enhanced for early diagnosis of STIs. However, it is still necessary to increase the public health measures to achieve a better result, such as the integrated management of STI cases (diagnostic circuit, identification and referral), improve the mechanism of notificable diseases and integrate a partner notification program for new STI cases.

MSM are still at risk for HIV infection despite 3 decades of prevention efforts, the rise in HIV and other STI needs to be reversed soon [28]. Continuing to monitor changes in the epidemiology of STI, and identifying the most affected 
groups should permit redesigning preventive programs, with the goal of finding the most efficient ways to reach these populations. In our setting, we consider that priority actions should be the promotion of measures to improve condom use, health education, treatment and particularly early diagnosis by investigating sexual partners due to the effectiveness in reducing morbidity and mortality $[29,30]$.

\section{Abbreviations}

STI: Sexually transmitted infections; MSM: Men who have sex with men; HAART: Highly active antiretroviral therapy; LGV: Lymphogranuloma Venereum; MSW: Men who only have sex with women; WSM: Women who have sex with men; $\mathrm{Cl}$ : Confidence Intervals.

\section{Competing interests}

The authors declare that they have no competing interest.

\section{Authors' contributions}

MPM, GdOP and CJA have designed the study. MPM has analysed the data supported by GdOP. MPM had written the article supported by GdOP and CJA. MPM, GdOP, CJA, BMJ, MC, OI, KH, GM, HV, VM, RE, VJ, MG, SMA, MA, VA, $A M, M J M$ and all the other members of HIV Surveillance Group commented on drafts of the manuscript and approved the final version.

\section{Authors' information}

Not applicable.

\section{Acknowledgments}

Our thanks to the doctors notifying cases of infection, and to staff of the Epidemiology Service, Barcelona Public Health Agency.

Members of the HIV Surveillance Group: Roser Clos, Sonia Gil, Eva Masdeu, Pere Simon, Pilar Gorrindo (Agència de Salut Pública de Barcelona); Pere Domingo, Maria G Mateo, Maria M Gutiérrez, Josep Cadafalch (Hospital de la Santa Creu i Sant Pau, UniversitatAutònoma de Barcelona); Maider Arando, Pere Armengol, Vicenç Falcó (Hospital Vall de Hebron, Universitat Autònoma de Barcelona), Ana Guelar, Teresa Carbonell (Hospital Universitari del Mar); Carlos Muñoz, José I Pérez, Felipe García, José L Blanco, Esteban Martínez, Josep Mallolas, Josep M Gatell (Hospital Clinic-IDIBAPS. University of Barcelona).

\section{Author details}

'Epidemiology Service, Agencia de Salut Pública de Barcelona, PI. Lesseps, 1, 08023 Barcelona, Spain. ${ }^{2}$ Teaching Unit of Preventive Medicine and Public Health, PSMAR-UPF-ASPB, Barcelona, Spain. ${ }^{3}$ Consorcio de Investigación Biomédica en Red de Epidemiología y Salud Pública (CIBERESP), Barcelona, Spain. ${ }^{4}$ Infectious Diseases, Hospital Vall de Hebron, Universitat Autònoma de Barcelona, Barcelona, Spain. ${ }^{5}$ Hospital Clinic-IDIBAPS, University of Barcelona, Barcelona, Spain. Infectious Diseases, Hospital del Mar, Barcelona, Spain. ${ }^{7}$ Infectious Diseases Unit, Hospital de la Santa Creu i Sant Pau, Universitat Autònoma de Barcelona, Barcelona, Spain. ${ }^{8}$ Departament de Justicia, Direcció General de Serveis Penitenciaris i de Rehabilitació, Barcelona, Spain.

${ }^{9}$ Fundació Puigvert, Barcelona, Spain.

Received: 4 February 2015 Accepted: 23 September 2015 Published online: 05 October 2015

\section{References}

1. European Centre for Disease Prevention and Control. Annual Epide miological Report 2013. Reporting on 2011 surveillance data and 2012 epidemic intelligence data. Stockholm: ECDC; 2013. Available at: http:// www.ecdc.europa.eu/en/publications/Publications/annual-epidemiologicalreport-2013.pdf.

2. Elford J, Jeannin A, Spencer B, Gervasoni JP, van de Laar MJ, Dubois-Arber F. HIV and STI Behavioural Surveillance Mapping Group. HIV and STI behavioural surveillance among men who have sex with men in Europe. Euro Surveill. 2009;14(47). Available online: http://www.eurosurveillance.org/ ViewArticle.aspx?Articleld=19414. European Centre for Disease Prevention and Control/WHO Regional Office for Europe: HIV/SIDA Surveillance in
Europe 2012. Stockholm: European Centre for Disease Prevention and Control; 2013. Available at: http://www.ecdc.europa.eu/en/publications/ Publications/hiv-aids-surveillance-report-2012-20131127.pdf.

3. UNAIDS. Global report: UNAIDS report on the global AIDS epidemic 2013; 2013. Available at: http:/www.unaids.org/sites/default/files/en/media/ unaids/contentassets/documents/epidemiology/2013/gr2013/ UNAIDS_Global_Report_2013_en.pdf

4. European Centre for Disease Prevention and Control. Thematic report: Men who have sex with men. Monitoring implementation of the Dublin Declaration on Partnership to Fight HIV/AIDS in Europe and Central Asia: 2012 Progress Report. Stockholm: ECDC; 2013. Available at: http:// www.ecdc.europa.eu/en/publications/Publications/dublin-declarationmonitoring-report-men-who-have-sex-with-men-october-2013.pdf

5. European Center for Disease Prevention and Control. Sexually Transmitted Infections in Europe, 1990-2009. Stockholm: ECDC; 2011. Available at: http:// ecdc.europa.eu/en/publications/Publications/ 110526_SUR_STI_in_Europe_1990-2009.pdf.

6. Fenton KA, Imrie J. Increasing rates of sexually transmitted diseases in homosexual men in Western Europe and the United States: why? Infect Dis Clin North A. 2005;19(2):311-31. Available at: http://www.ncbi.nlm.nih.gov/ pubmed/15963874.

7. European Centre for Disease Prevention and Control. Annual Epidemiological Report 2012. Reporting on 2010 surveillance data and 2011 epidemic intelligence data. Stockholm: ECDC; 2013. p. 37-53. Available at: http://www.ecdc.europa.eu/en/publications/Publications/AnnualEpidemiological-Report-2012.pdf.

8. Mirandola M, Folch Toda C, Krampac I, Nita I, Stanekova D, Stehlikova D, et al. SIALON network. HIV bio-behavioural survey among men who have sex with men in Barcelona, Bratislava, Bucharest, Ljubljana, Prague and Verona, 2008-2009. Euro Surveill. 2009;14. Available at: http:// www.eurosurveillance.org/images/dynamic/EE/N14N48/art19427.pdf.

9. Zetola NM, Bernstein KT, Wong E, Louie B, Klausner JD. Exploring the relationship between sexually transmitted diseases and HIV acquisition by using different study designs. J Acquir Immune Defic Syndr. 2009:50(5):54651. Available at: http://www.ncbi.nlm.nih.gov/pmc/articles/PMC2680242/pdf/ nihms-94887.pdf.

10. Departament d'Estadística. Ajuntament de Barcelona. Instituto Nacional de Estadística. Institut d'Estadística de Catalunya. Available at: http:// www.bcn.cat/estadistica/castella/index.htm

11. Decret $67 / 2010$, de 25 de maig, pel qual es regula el sistema de notificación de malalties de declaració obligatòria i brots epidèmics al Departament de Salut. DOGC. Diari Oficial de la Generalitat de Catalunya, 8 Juliol 2010; núm. 5666.

12. Rodríguez-Sanz M, Morales E, Pasarín MI, Borrell C. Enquesta de Salut de Barcelona 2011. Barcelona: Agència de Salut Pública de Barcelona; 2012.

13. SPSS for Windows. Chicago: SPSS Inc 2009;18.

14. Ley de Protección de Datos de Carácter Personal. L. №. 15/1999 (13 diciembre 1999). BOE núm. 298; 1999. Available at: http:// www.boe.es/boe/ dias/1999/12/14/pdfs/A43088-43099.pdf]

15. Health Protection Agency. HIV in the United Kingdom: 2011 Report. London: Health Protection Services, Colindale; 2011. Available at: http:// www.ivecic.com/uploads/7/5/4/1/7541913/hiv_in_the_uk_2011_report.pdf.

16. NYC DOHMH HIV. Epidemiology and Field Services Program Semiannual Report. October 2011. Available at: http://www.nyc.gov/html/doh/ downloads/pdf/dires/2011_2nd_semi_rpt.pdf.

17. International AIDS Society-USA. Sexually Transmitted Infections and HIV: Epidemiology and Interventions. Top HIV Med. 2010;18:138-42. Available at: http://www.iasusa.org/sites/default/files/tam/18-4-138.pdf.

18. Díaz A, Díez M, Cano R. Vigilancia epidemiológica de las infecciones de transmisión sexual, 1995-2010. Boletín epidemiológico semanal. Centro Nacional de Epidemiología. Instituto de Salud Carlos III. 2012;20(7):30-35.

19. Jin F, Prestage GP, Templeton DJ, Poynten IM, Donovan B, Zablotska I, et al. The impact of HIV seroadaptive behaviors on sexually transmissible infections in HIV-negative homosexual men in Sydney Australia. Sex Transm Dis. 2012;39:191-4. Available at: http://www.ncbi.nlm.nih.gov/pmc/articles/ PMC3282017/pdf/nihms-342155.pdf.

20. Folch C, Muñoz R, Zaragoza K, Casabona J. Sexual risk behaviour and its determinants among men who have sex with men in Catalonia, Spain. Euro Surveill. 2009;14. Available at: http://www.eurosurveillance.org/images/ dynamic/EE/N14N47/art19415.pdf. 
21. McConnell JJ, Bragg L, Shiboski S, Grant RM. Sexual Seroadaptation: Lessons for Prevention and Sex Research from a Cohort of HIV-Positive Men Who Have Sex with Men. PLoS ONE. 2010;5. Available at: http:// www.ncbi.n/m.nih.gov/pmc/articles/PMC2809110/pdf/pone.0008831.pdf.

22. Vargas-Leguas H, Garcia de Olalla P, Arando M, Armengol P, Barbera M, Vall $M$, et al. Lymphogranuloma venereum: a hidden emerging problem, Barcelona, 2011. Euro Surveill. 2012;17. Available at: http:// www.eurosurveillance.org/images/dynamic/EE/N17N02/art20057.pdf.

23. Tortajada C, García de Olalla P, Diez E. Hepatitis a among men who have sex with men in Barcelona, 1989-2010: insufficient control and need for new approaches. BMC Infect Dis. 2012;12:11. doi:10.1186/1471-2334-12-11. Available at: http://www.ncbi.nlm.nih.gov/pmc/articles/PMC3282664/pdf/ 1471-2334-12-11.pdf.

24. Pascoe EA, Smart RL. Perceived discrimination and health: A meta-analytic review. Psychol Bull. 2009;135(4):531-54. Available at: http:// www.ncbi.n/m.nih.gov/pmc/articles/PMC2747726/pdf/nihms134591.pdf.

25. Brewer MB. Social identity and close relationships. In: Forgas JP, Fitness J, editors. Social relationships: Cognitive, affective, and motivational processes. New York: Psychology Press; 2008. p. 167-84.

26. Grupo de trabajo sobre ITS. Diagnósticos de sífilis y gonococia en una red de centros de ITS: características clínico-epidemiológicas. Resultados julio 2005-diciembre 2011. Centro Nacional de Epidemiología/Subdirección General de Promoción de la salud y Epidemiología - Plan Nacional sobre el Sida, 2014. Available at: http://www.isciii.es/ISCIII/es/contenidos/fd-servicioscientifico-tecnicos/fd-vigilancias-alertas/fd-enfermedades/fd-sida/ Informe_ITS_2005-2011.pdf.

27. Garcia de Olalla P, Molas E, Barberà MJ, Martín S, Arellano E, Gosch M, et al. Effectiveness of a pilot partner notification program for new HIV cases in Barcelona, Spain. PLoS ONE. 2015;10(4):e0121536.

28. Haar K, Amato-Gauci AJ. European men who have sex with men still at risk of HIV infection despite three decades of prevention efforts. Euro Surveill. 2015 Apr 9;20(14).

29. Brewer DD. Case-finding effectiveness of partner notification and cluster investigation for sexually transmitted diseases/HIV. Sex Transm Dis. 2005:32(2):78-83.

30. Low N, Broutet N, Adu-Sarkodie Y, Barton P, Hossain M, Hawkes S. Global control of sexually transmitted infections. Lancet. 2006:368(9551):2001-16. Available at: http://www.sciencedirect.com/science/article/pii/ S0140673606694828.

\section{Submit your next manuscript to BioMed Central and take full advantage of:}

- Convenient online submission

- Thorough peer review

- No space constraints or color figure charges

- Immediate publication on acceptance

- Inclusion in PubMed, CAS, Scopus and Google Scholar

- Research which is freely available for redistribution

Submit your manuscript at www.biomedcentral.com/submit 